\title{
The Use of Metaphor in News Reports : News Reports on EU Economic Crisis as A Case Study
}

\author{
Ai Xirong \\ Foreign Languages Department \\ Yulin University \\ Yulin City, Shaanxi Province, P. R. China \\ E-mail: 353217985@qq.com
}

\begin{abstract}
News reporting involves many uses of figures of speech, of which metaphor is used widely. Through the use of metaphor, news reports will be more vivid and thus more attractive to the audience. Besides, the application of metaphor in news reports can have an impact on the audience's cognition. Taking news reports about the EU (European Union) economic crisis for case study, this paper analyzes the use of metaphor and elaborates on its functions in news reports.
\end{abstract} Crisis

Keywords-Metaphor;News;EU;Cognition; Economic

\section{INTRODUCTION}

News reporting involves many uses of figures of speech, of which metaphor is used widely. On the one hand, through the use of metaphor, news reports will be more vivid and thus be more attractive to the audience. On the other hand, the application of metaphor in news reports can have an impact on the audience's cognition. In the news reports about EU economic crisis, metaphors have been used widely and the dual functions of metaphor are demonstrated clearly.

\section{METAPHOR AND METAPHORS IN NEWS REPORTS}

Metaphors are among the most studied and analyzed linguistic devices in the history of human communication. [1] The American Heritage Dictionary defines metaphor as "a figure of speech in which a word or phrase that ordinarily designates one thing is used to designate another, thus making an implicit comparison." [2] From the perspective of traditional rhetoric, metaphor is the substitution of one thing to another thing or one experience to another experience. Concretely speaking, through human's cognition and reasoning, it projects or maps one conceptual domain to another conceptual domain and thus establishes the mutual connection between differing concepts. ${ }^{[3]}$ As a rhetoric means, the use of metaphor is to achieve special rhetoric or communicative effect, just being the decoration and modification of a language. Overall, we know nothing at all about things outside the world of daily life. The only way for human perception senses to perceive the world is to compare the abstract world with the world of daily life.
This can help people understand the abstract world by using familiar referents. Such application of the known to the unknown constitutes the essence of metaphor. ${ }^{[4]}$

But from the perspective of modern metaphor theory, metaphor is not only a meaning of rhetoric, but also a way of thinking and cognition. Metaphors are pervasive in everyday life, not just in language but in thought and action. Human conceptual system is metaphorically structured and defined. Therefore, metaphor is not only a language form, but also a way of thinking. Metaphor is a universal human cognitive tool, and is a process of recognizing, understanding, thinking and expressing one thing via anther thing. Metaphor can construct our perception of reality, build our way of thinking, and also shape our behavior. ${ }^{[5]}$ Derrida also holds that metaphor is the symbol of the whole language system and regards metaphor as a kind of cognitive activity and expressive behavior. ${ }^{[6]}$ Metaphor has the function of governing human judging and reasoning and of influencing people's behavior. Human cognition is largely dependent on metaphor and metaphorical thinking. It can be said that metaphor permeates in human thinking and behavior.

Language and thinking are experiential, and have a neurological basis. We can construct and understand the concept and its meaning because they are derived from our bodily experiences. ${ }^{[7]}$ However, because people's personal experiences are limited, their acquisition of information relies on the media to a large extent, so that people's perception of things is largely dependent on media reports and media language. The media provides us with a framework for understanding the world, and it then will impact on our observation, cognition and judgment of the objective world. ${ }^{[8]}$ The media plays a very important role in shaping society. ${ }^{[9]}$ For the general public, especially for those far from the EU, their feeling, experience and cognition about the EU economic crisis are mainly obtained through media reports.

Media language is rich and colorful, containing a lot of rhetorical devices, and the use of metaphor is very common. When the media report an event, they try their best to attract the audience's attention and arouse public concern, and the use of metaphor helps to achieve this purpose. The use of metaphor in news reports, on the one hand, meets the demand of attracting the audience, and on the other hand, it has the function of leading and 
constructing the audience's cognition of the event. Maybe this function is achieved unconsciously, but it exists objectively. Discourse is not only the objective description of one event or object, but also has the function of constructing the reality, and media discourse is especially prominent with regard to this function. Through the metaphorical description, the media reveal an event or an object vividly. And by being repeated and strengthened, the metaphor is accepted by the audience and becomes one of the audience's cognitive modes. In today's multimedia world, this effect is particularly prominent. A word or a song may be accepted and pursued in a short span of time by the audience. The same is true of metaphor in media reports, having the possibility of such rapid dissemination. Therefore, with the help of the media, the cognitive function of metaphor becomes more prominent, and exerts a powerful influence on the audience and the society.

\section{AN ANALYSIS OF THE USE OF METAPHORS IN NEWS REPORTS ABOUT EU ECONOMIC CRISIS}

With regard to EU economic crisis, there have been a lot of reports in the media, in which metaphors are used widely. These metaphors describe and demonstrate the situation of the EU in the economic crisis and help the public get the knowledge about the EU's situation. Meanwhile, in the process of the spreading of these metaphors, the audience gradually accepts and finally internalizes the metaphors used in the news reports, which helps the audience form the cognition of the EU. In the news reports about the EU in economic crisis, the most widely used metaphors are those that are related to disease or sickness. It can be said that the overall image of the EU in the economic crisis before the audience is "a sick person".

\section{A. The Use of Metaphors in the Description of the EU'S Situation}

After the EU plunges into the economic crisis, the media use a great number of metaphors in the news reports. Via these reports, the audience forms their cognition of the EU. In such reports, the use of metaphors contributes to the construction of the EU's image of "a sick person". As early as in April of 2007, a report in The Economist describes Portugal as "a new sick man of Europe". In June of 2009, with the economy of Greece getting worse and worse, the label "sick man of Europe" is used to refer to Greece. In October of 2007, a report of Washington Post is titled Myths about Sick Old Europe. Later, more EU nations get "sick" and France is no exception. In November 1st, 2012, a report in Paris Games Week is titled France, the New Sick Man of Europe? It is thus clear that the EU economic crisis has become more serious and diffuse. Likewise, Chinese media use the similar metaphors. For example, there are such descriptions as "Sick EU messing protection medicine" (Oversea Edition of People's Daily, 2012/8/13), "Sick man of Europe waiting for institutional salvation" (Yangtze River Daily, 2011/19/9), "Greece is still in ICU" (Hainan Daily, 2012/3/10), "EU members having frequent low fever before the summit” (China Securities Paper, 2012/6/27).

Through the use of metaphors, the above news reports contribute to the audience's understanding of the EU's situation that the EU has got sick and becomes a sick person. Thus, the impression comes into the audience's mind that the situation of EU in economic crisis is serious and difficult to deal with.

\section{B. The Use of Metaphors in the News Reports About EU's Solution to the Crisis}

Now that the EU has got "sick", it should be treated. The EU is stuck by the economic crisis and measures must be taken to get rid of the crisis. In the news reports about it, metaphors are used frequently. Generally speaking, when people get sick, they have to take medicine, be treated, or even have surgeries. So, in the media reports, these words appear frequently. In the Chinese media, there have been headlines such as "the EU seeking relief on three prescriptions", "the rating agencies unsatisfied with the EU's prescription", "the EU debt crisis "prescription" released", "EU finance ministers will write out prescription to the European debt mess", "Can new loans save Greece?", "Banking 'checkup' not be the EU's quick cure”, "whether the crisis can be cured remains a question", "The new prescription can't cure the old disease of the EU debts". Of course, such statements are too numerous to enumerate. It can be seen that the patient, the EU, has taken a lot of medicines and tried a variety of prescriptions and various treatments.

In the foreign media reports, the EU's response to the economic crisis are also described with the words such as medicine, cure, treatment, and save. In September 2011, Economist publishes a report titled European financial crisis: how to save the euro? Another report in July 2012 in Economist is titled The Euro Crisis: Bad medicine. A report in Telegraph is titled 1930s Medicine pushes Europe back into double dip recession. In September 2012, a report in Guardian is titled Leaders face very hot autumn as they battle to save euro European. And the website vox publishes an article headlined the European Misdiagnosing Crisis: from Asia Perspectives. A report in The National is headlined EU leaders still divided over euro for cure crisis.

The above is only a small part of the reports about the cure of the EU economic crisis. These medical metaphors show the scene that the EU, infected with the disease, is seeking treatments, that is, try to get out of the economic crisis.

\section{The Use of Metaphors in the Description of Prospects for the EU Economic Crisis}

When a patient has got serious illness, he or she will seek treatments everywhere. Will he or she recover or get improved? This is just about the prospects of the EU economic crisis in the media reports. Therefore, in these kinds of reports, the metaphorical word such as health, heal, rehabilitation, and recovery are used a lot. For example, in a website report in China has such contents: the EU Barroso: "the financial crisis has not yet healed". An article in FT Website in Chinese has the following contents: The problem is whether the European economy will recover health through the economy led by the private sector? Europe will expect the United States to (temporarily) recover through increased spending. ${ }^{[10]}$

Similarly, in Western media reports, words like healthy and recovery are also frequently used. For example, an article in The Australian writes: "Healthy Australia can provide stimulus in EU crisis". A Guardian report in March 2012 writes: "Europe faces 'long, hard road' to 
recovery". Another report in Guardian is titled "European Debt Crisis Recovery Outlook is Not Optimistic". Although these reports are filled with words like "recovery", but they are mostly negative news - the patient is far from full recovery and the EU economic crisis has not been well solved. This is the image of the EU that these metaphors have brought to us, which more or less corresponds to the actual situation of the EU at that time. Of course, this image does not make people excited. In the era of globalization and interdependence, the EU's "disease" has also affected other regions. So, a report in Washington Post says that "the US economic recovery tied to European Debt Crisis". It is also reported that OECD (Economic Development and Cooperation Organization) thinks that "Euro crisis could hamper global recovery".

\section{CONCLUSIONS}

Through the use of metaphors, the media vividly shows a picture of the EU's situation of "getting sick, healing and rehabilitation", which is accepted by the audience and becomes the audience's cognitive schema, so that the audience has a new understanding of the European Union. From the use of metaphors in the EU economic crisis of, we can see that metaphor not only has the function of rhetoric, but also has the function of cognitive construction. Therefore, our understanding of metaphor needs to shift from its traditional rhetorical function to its function of social construction and human cognitive construction, so that we can have a deeper insight into the nature of social facts and human cognition and better dig out the social value and functions of metaphors.

\section{REFERENCES}

[1] Michael P. Marks, Metaphors in International Relations Theory. New York: Palgrave Macmillan, 2011

[2] American Heritage Dictionary of the English Language. Boston, MA: Houghton Mifflin, 1992

[3] Yang Weidong and Dai Weiping, "The Metaphor We Live on, " Crazy English (Teachers' Edition), vol.4, Oct. 2007, pp. 61-63

[4] Rainer Hülsen, "On Metaphor's Function of Social Construction: the EU Expansion as An Example, "International Review, vol.26, May 2008, pp. 15-22

[5] G. Lakoff, M. Jonson, Metaphors We Live by. Chicago: The University of Chicago Press, 1980

[6] J. Derrida, Margins of Philosophy. Chicago: The University of Chicago Press, 1982.

[7] Gao Yuan and Li Fuyin(eds.), Ten Lectures on Cognitive Linguistics by George Lakoff. Beijing: Foreign Language and Research Press, 2007

[8] Lei Li, "Analysis of the Media's Influence on the Audience's Cognition, " Youth Journalist, vol.67, July 2009, pp. 37-38

[9] Thomas K. Fitzgerald, Metaphor of Identity. New York: State University of New York Press, 1993

[10] http://www.ftchinese.com/story/001026737/?print=y 